\title{
EMPATHIC AND PEACEBUILDING GESTURES: AN ANALYSIS OF GREETING GESTURES ACROSS CULTURES
}

\author{
JOANNA PUPPEL, ALICJA ROZPENDOWSKA
}

"We cannot live only for ourselves. A thousand fibers connect us with our fellow-men; and along those fibers, as sympathetic threads, our actions run as causes, and they come back to us as effects."

Herman Melville

\begin{abstract}
Communication process allows people to receive and send messages through verbal and nonverbal resources which play an important role in healthy interpersonal acts. While verbal communication has been the subject of many studies, the present study aims to focus mainly on the nonverbal aspect that is greeting gestures. In this article we shall analyze which greeting gesture, that is widely used across different cultures may evoke a feeling of empathy and thus build peaceful interactions so needed in human communication nowadays.
\end{abstract}

Key words: empathy, peacebuilding, gestures, greeting gestures

\section{Greeting gestures across cultures}

We assume that in a non-conflicting culture with public space being managed empathically, that is, the one which is based on peacebuilding gestures, greeting gestures occupy a central position in the human symbolic capital, owing to its manual interpersonal communicative power. (Puppel, 2019).

Gestures play highly crucial role in all aspects of interpersonal communication. Thanks to them human communication agents are able to communicate with each other and provide many messages which convey verbal and also nonverbal meanings. Even though there exists many different types of gestures, greeting ones are 
perceived as an essential and crucial part of everyday life. They are highly important in interpersonal communication used in different communicative niches. Greeting gestures are vital as a presenter of a first image creator. First impressions are very significant for a variety of reasons. On the one hand greeting gestures are culturally diverse, but on the other hand it is important for people to be aware of this in order to communicate positively and without misunderstandings.

One can distinguish many forms of greeting gestures depending on culture. In this article we would like to present some greeting gestures which can be found across different cultures.

\subsection{Handshake}

Among many greeting gestures people perform every day, handshake is the most common one. Handshake is said to be one of the most common and most taken-forgranted gesture which is used by human beings while meeting each other (Puppel, 2019). Nevertheless it may differ across the world. In various cultures handshakes are not performed in the same way.

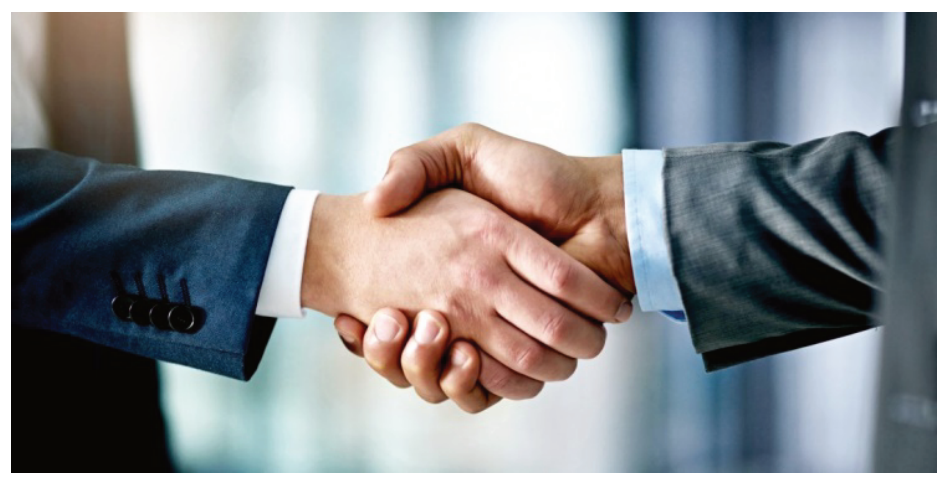

Illustration no 1 . Handshake as a greeting gesture

The free hands have made it possible for humans to develop and perform an important hand-touching and culture-determined ritual, the handshake, in the procedure of human-to-human encounter (Puppel, 2019). According to Merriam Webster's Learner's Dictionary, handshake is the act of grasping someone's right hand with your right hand and moving it up and down. What is more, the handshake has the general meaning of equality in the sense of mutual denials of deference to self and mutual expressions of respect for the other (Hall and Hall, 1983: 251). From nonverbal perspective, handshake is an act of touch and greeting that is performed between two persons. Therefore, by observing handshake interactions, many social and 
interpersonal messages can be discerned. Nevertheless, handshake has a communicative function and replaces verbal expression such as "hello" (Huwer, 2003: 26). According to Schroeder et al. (2019), handshakes are seen as ritualistic behavior and are considered a "greeting ritual" because they are commonly used at the start of social interactions. In addition, it is important to mention that handshake is often the first behavioral act which occurs when people meet and through handshake the information is conveyed (Barrich, et al., 2008: 1140). Moreover, by this non-violent attitude, "the handshake is used by communicators to open up an agenda, this is, it opens up a common ground for peaceful exchange of information and for making a familiar space which involves the handshake as a strong signal sent to the other human being(s) as regards the readiness both to cooperate and receive reciprocity" (Puppel, 2019: 140). The significance of a handshake is not circumscribed to a specific national group. It is rather perceived worldwide as an interpersonal greeting gesture (Ponton, 2014: 60). However, it may be found across the globe, but there can be distinguished many nuances within gesture which may have significant impact on the meaning. Thus, there may appear different misunderstandings, hence it may cause numerous different meanings attached to the handshake as well as different styles of performing it (Ponton, 2014). As Ahmad (2015) observed firm, hearty handshake is a tradition in European countries. In addition, this grip is not so tight, and what is more, there is little or no shaking action. Nevertheless, the handshake in greeting is seen as a vital gesture and may imply various interpersonal interactions.

\subsection{Kissing as a greeting gesture}

Another example of greeting gesture is kissing, although it is a universal gesture, it is also one of the most difficult to research. In history, "written celebrations and deceptions of the kiss often seem to reflect literary and aesthetical standards rather than actual practice" (Frijhoff, 1991: 210). What is more as Frijhoff (1991) observed

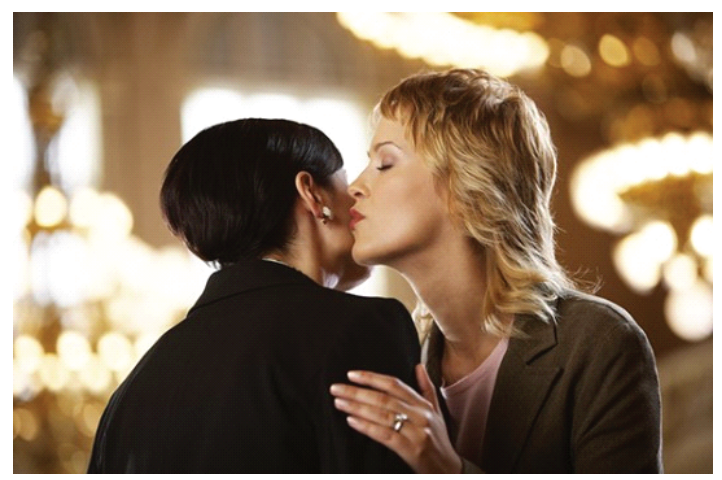

Illustration no. 2. Kissing as a greeting gesture 
kissing, unlike many other gestures, is both a gesture and a ritual. He added that it is simple but complete gesture, a bodily expression of social interaction which is a cultural practice in itself. Being a cultural practice, kissing as greeting gesture involves not only a language of gesture but also a range of meanings (Frijhoff, 1991). Kissing is a common greeting gesture for example in France, Spain, Italy. Most people from these countries expect to be kissed on both cheeks as a greeting ritual (Ahmad, 2015). Moreover, the kiss does not only remain to the sphere of intimacy or express passion, love or affection. It is important to mention that kissing "is charged with a variety of meanings corresponding to the precise social and cultural context in which it is given" (Frijhoff, 1991: 211). Additionally, in the Mediterranean countries such greeting gesture is accepted between both, same sex and the opposite sex, and these 'little kisses' are treated as purely positive and are well accepted norms of the Mediterranean societies.

Nevertheless, even kissing as a greeting gesture differs across cultures and countries and as a result it can adopt many different meanings and forms.

\subsection{Bowing as a greeting gesture}

Another greeting gesture is a Japanese bowing which is considered to be a form of loyalty, courtesy, politeness and personal responsibility. When it comes to meetings and greeting, Japanese people bow. The bow as o form of greeting gesture is highly regarded in order to show respect and is very much appreciated by the Japanese

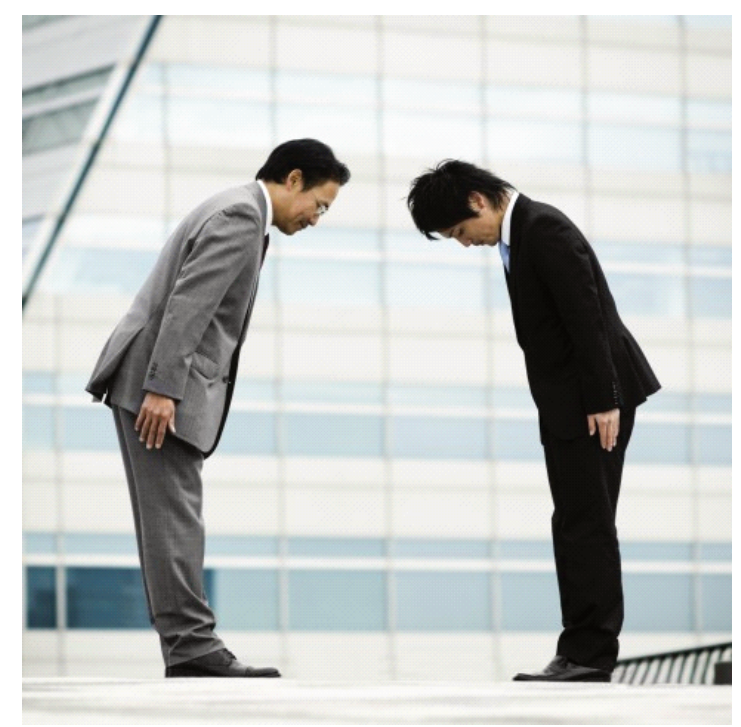

Illustration no. 3. Bowing as a greeting gesture 
people. Ahmad (2015) pointed out that for Japanese society, in most of the situations, bowing would be the only polite gesture to make, since this culture belongs to noncontact cultures and any body contact is rather perceived as taboo, and treated as an unwanted behavior. What is also worth mentioning is that, Japanese bowing is gender based. There exists different forms of greetings reserved for men and women. As Ahmad (2015) observed men and women bow differently. Men usually keep their hands at their sides, while women put their hands together along their tights. Additionally, people who are of lower status bow longer and lower. According to Ahmad (2015) Japanese greetings gesture consist of three degrees of bowing:

- 15 degree bow - it is the most informal bow and is used for casual greetings. It is obligatory on the part of a greetee to bow before the greeter. In addition, it is highly impolite not to return a bow if a greeter bows to a greetee.

- 30 degree bow - it is common when greeting customers or simply when thanking someone. It can also be observed in semi-formal business communicative situations.

- 45 degree bow - it is the most formal type of bow. It signifies deep gratitude, a respectful greeting, a formal apology, asking for favors, etc.

\subsection{Bowing and handshaking as a greeting gesture}

Another greeting gesture can be observed in China. While meeting and greeting, Chinese may nod or bow and add handshakes which have become increasingly common (IS1). As Ahmad (2015) observed it is due to the influence form the Western culture and thus handshake is widely used in China. However, a nod of the head

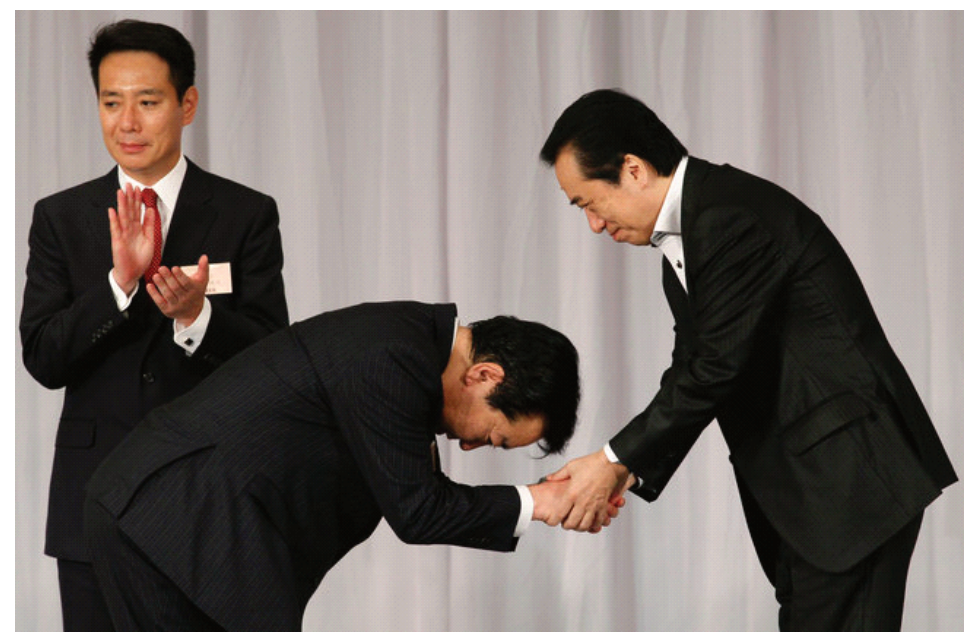

Illustration no. 4. Bowing and handshake as a greeting gesture 
or slight bow will be sufficient. What is more, in Western cultures while greeting, there also appears a smile, Chinese people mostly do not smile during a greeting gesture. Chinese people have the attitude of keeping their feelings inside them than showing emotions openly and publicly (Ahmad, 2015: 64). What is more, as Ahmad (2015) pointed out their handshake is rather light and sometimes might be prolonged. In Chinese culture men and women may shake hands, however, woman is obliged to extend her hand first, while men should wait to shake hands. While meeting with elderly people, it is a senior who begins greetings. What is more, it is required to greet the oldest, most senior person before others (IS1). Ahmad (2015) added that the handshake should be gentler and definitely accompanied by a slight nod. Furthermore, it can be observed that the vast majority of older Chinese lower their eyes while greeting in order to show a respect. There also exists a norm that while greeting friends, one should say "how do you do", nod head or shake hands. This form of greeting is performed between the same sexes and the opposite ones as well. A handshake may be prolonged than normal one in Western cultures and this signifies a gesture of respect (Ahmad, 2015: 64-65).

\section{5. 'Namaste' as a greeting gesture}

India is one of the most diverse countries in the world. Indian greeting custom is 'Namaste'. "One commonly does this by a slight bow made with hands pressed together, palms touching and fingers pointed upwards, in front of the chest. What is more, 'Namaste' may be translated as 'I bow to you' (IS2). It is worth mentioning

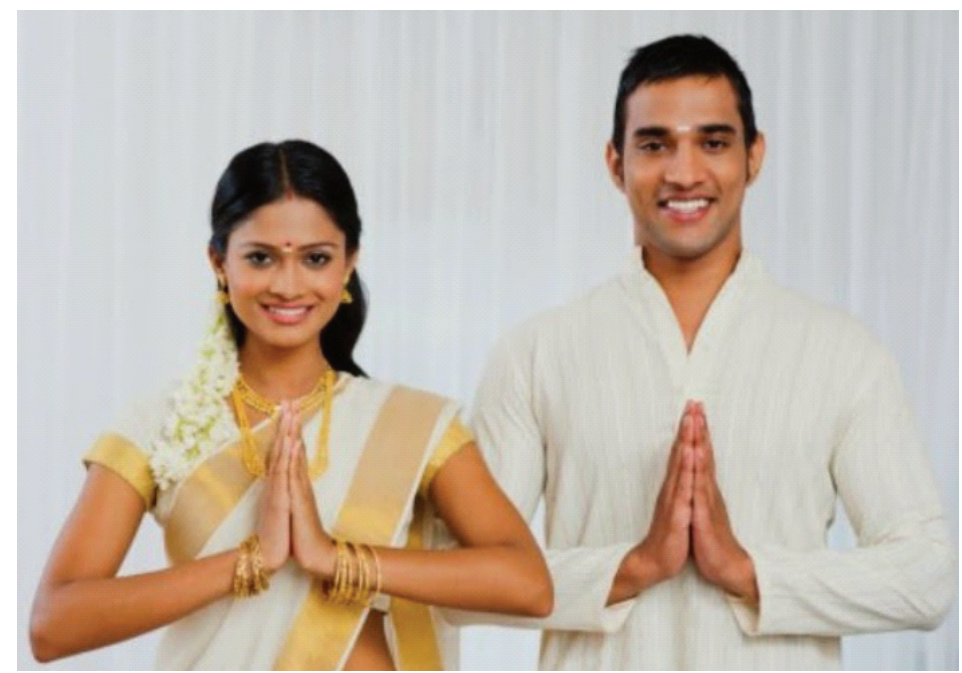

Illustration no. 5. 'Namaste' as a greeting gesture 
that this greeting gesture is perceived as a humble greeting which is done straight from the heart and reciprocated accordingly (Kumar, 2001: 2). Moreover, 'Namaste' is not only treated as a sign of recognition but also as an expression of happiness by both participants of the given gesture.

"Namaste is a greeting thus is a mosaic of movements and words constituting an information of affirmative thoughts and sentiments (...). It also has emotional and spiritual significance. In fact it is said that in namaste the hands are put together like a knife so that people may cut through all differenced that may exist, and immediately get to the shared ground that is common at all people of all cultures" (Kumar, 2001: 4).

It is important to mention that 'Namaste' is perceived as highly friendly greeting gesture. What is more, this type of gesture is widely used and dates back to c. 4000 years ago when it appears on the clay seals of the Indus Valley Civilization (IS2). As 'Namaste' is reciprocated, thus, it is perceived as an attempt to unite the spiritual oneness among two people. What is also important, in contrast to shaking hands or kissing, 'Namaste' is a non-touch form of highly respectful greeting and is supposed to be used while greeting a person of different gender, age or social status (Singh, et al. 2000).

\subsection{Rubbing hands as a gesture}

Greeting gestures are very important part of social life. Malays greet each other with bringing palms together (as if to shake hands) and placing it between one's own (Ahmad, 2015: 67). In addition, it is important to mention that Malays greeting gesture

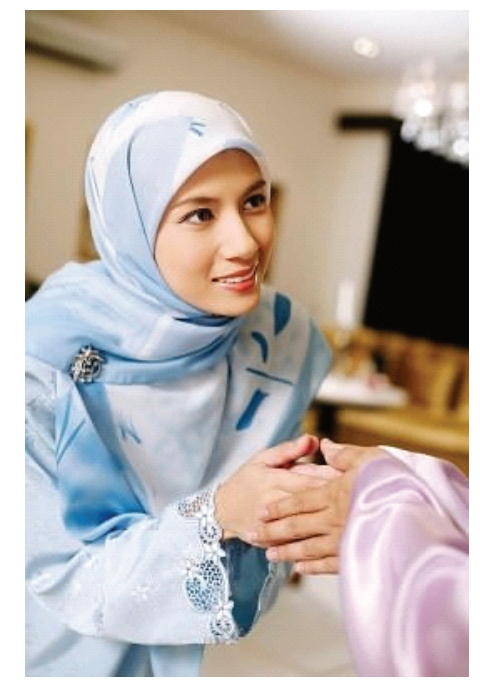

Illustration no. 6. Rubbing hands as a greeting gesture 
is called "salaam". People extend both hands and at the same time grasp their hands (like a double handshake) (IS3). However, in Malaysia greeting forms vary depending on the age, ethnicity and situation. For example, it is a norm that Malay women do not rub hands with men, unless women extend their hands first. Women may instead bow and place her hand on her heart as showing respect. Nevertheless, women can rub hands with women (IS3). What is more, after rubbing hands it is possible that they bring their hands to their hearts. This is a symbol of greeting showing the highest level of respect to other person (IS3).

\section{7. 'Mano' as a greeting gesture}

Greeting in Philippines is determined not only by the age but also by the relationship between people. The picture (see Illustration no 7) presents a 'mano' greeting gesture which means 'be blessed'. In this country, people are greeted by taking one of their hands gently and pressing it to their forehead (IS4). It is also important that the person giving the greeting, bows slightly towards the greeted person. It is important to mention that this type of gesture is mostly performed towards elders and is a way of showing respect. It may also mean accepting a blessing from the elder. While performing and offering the 'mano', a person makes himself/herself subservient to the elders and thus accepts their blessing and wisdom (Scroope, 2017). In addition 'mano' greeting gesture is mostly performed towards people who are older by two or more generations. Nevertheless, this type of greeting gesture is old but still widely used.

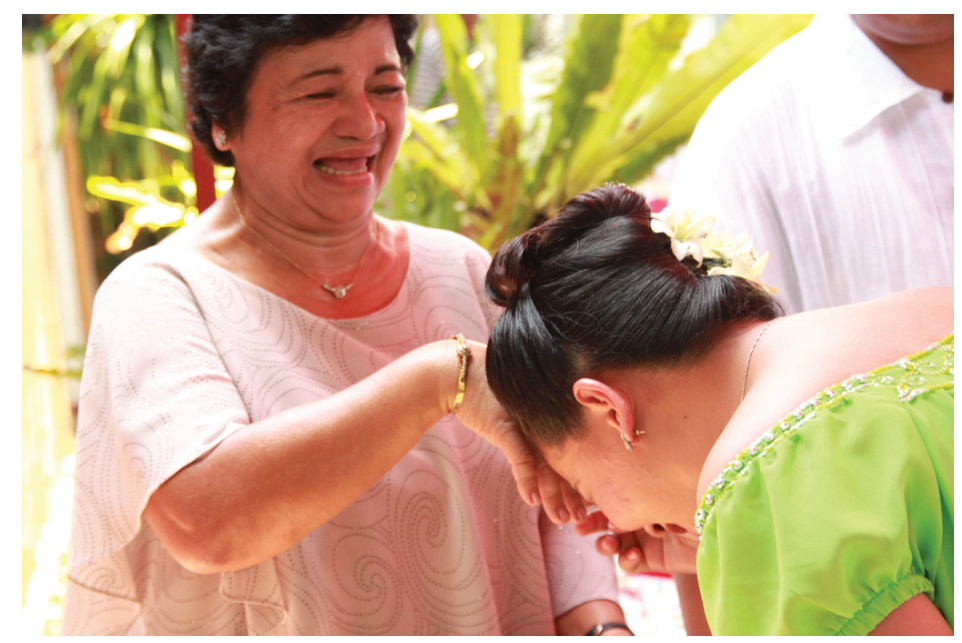

Illustration no. 7. 'Mano' as a greeting gesture 
"The Filipino culture has been heavily influenced by both Eastern and Western customs and traditions. From youth, Filipinos are taught to respect the elders, not only within the family, but those in the community as well, by the strangers or relatives. Filipinos believe that the elders have earned the respect of the younger generations not only through their age, but through their acquired wisdom and experience. The custom of mano dates to pre-colonial times, and is still followed in countries like Philippines or Malaysia" (Scroope, 2017).

Thus, paying and showing respect to elders emerges from the importance and significance of the role of the family in Filipino culture and 'mano' gesture is a highly valuable greeting custom.

\section{8. 'Hongi' as a greeting gesture}

Maori greeting gesture from New Zealand is similar to the Western kissing gesture, however, it carries far more contact procedures. This type of greeting gesture is named 'hongi'. It is performed by rubbing or touching noses. The 'hongi' tradition dates back to the origins of the Maori's culture, and it is a very essential part of it (IS5). As Lundmark (2009) pointed out the act of 'hongi' is more about pressing than rubbing. Firstly, a person places the forehead against the other person's forehead, and then they press noses together. Depending on different parts of New Zealand, pressing noses may be performed once, twice or even three times. It is important to mention that they also hold each other's hands, and breathe in simultaneously. This type of greeting gesture carries not only cultural but also spiritual significance:

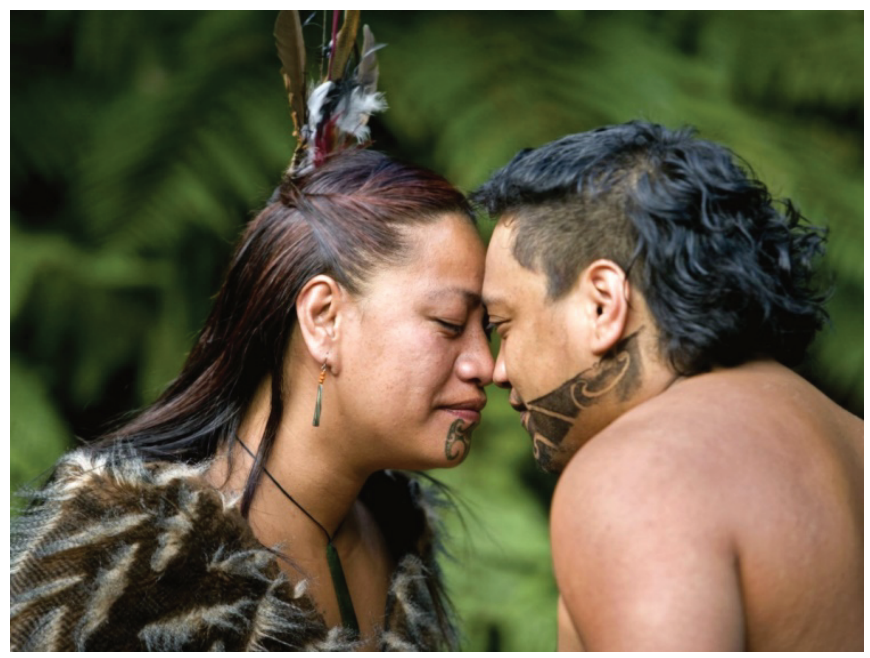

Illustration no. 8. 'Hongi' as a greeting gesture 
by sharing the 'breath of life' two strangers become friends, passers-by become guests and visitors become part of the community (Lundmark, 2009). Maori are highly connected with their heritage so the 'hongi' is not only reserved for traditional or cultural meetings but also it is treated as a common part of everyday life. This greeting gesture is possible to be performed between both Maori and non-Maori. It can be performed even on higher levels among for example politicians or diplomats during formal meetings (Lundmark, 2009: 26). The 'hongi' is perceived as more powerful than a common handshake. Through such close greeting gesture and exchanging breaths, they share essential aspects of living with one another (IS5). Thus, 'hongi' greeting gesture is considered not only as physical act but also as a spiritual one which is very significant in Maori communities.

\subsection{Sticking a tongue out as a greeting gesture}

Sticking one's tongue out is a Tibetan form of greeting gesture which is a sign of respect (White, 2014). This custom has a long history:

“A $9^{\text {th }}$ century Tibetan king, Lang Darma, known for his cruelty, had a black tongue. As Buddhists, Tibetans believe in reincarnation, and they feared that this mean king would be reincarnated. Consequently, for centuries Tibetans have greeted one another by sticking out their tongues demonstrating that they do not have black tongues, that they are not guilty of evil deeds, that they are not incarnations of malevolent king" (Dresser, 1997).

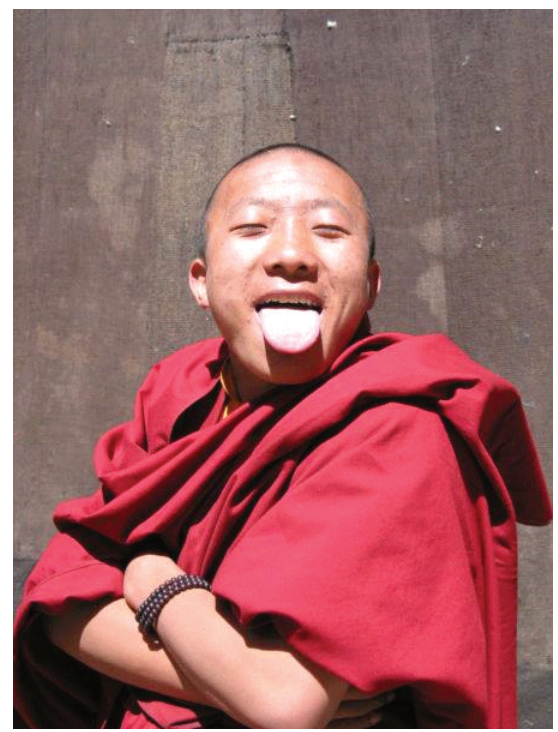

Illustration no. 9. Sticking a tongue out as a greeting gesture 
Nowadays, it is not so popularly used, nevertheless, in addition to being a greeting gesture, sticking one's tongue out is not only considered as showing agreement but also over years this gesture has evolved into a sign of respect (Dresser, 2015). Comparing Tibetan greeting gesture with for example the Western ones (handshake and kissing), it can be observed that sticking a tongue out is rather perceived as an impolite and rude kind of greeting. The cause of it is that sticking a tongue out in the Western cultures is a way of showing disrespect and/or dissatisfaction. Thus, it conveys different meaning depending on cultures.

\subsection{Rubbing noses as a greeting gesture}

Rubbing noses ('the nose kiss') as a greeting gesture is a common greeting ritual in Saudi Arabia. Saudi men who are very close friends may greet each other in such a way. Nevertheless, it is only performed when people are deeply loyal to one another (IS6). In Arabic culture, nose-rubbing has been passed from generation to generation. For them, it is an extraordinary custom of greeting, showing deep friendship and respect. What is more, at the same time it serves as a traditional code among the Bedouins. In fact, Arab people find nose as the most appealing part of the face and they treat is as their pride thus such greeting gesture is commonly used. Additionally, such greeting gesture is associated with pride and dignity. Moreover, through rubbing noses as a greeting gesture, people say how they are related to each other, but also nose being a symbol of pride and the most valuable part of the face, putting nose close to each other is simply saying 'we are very close friends' (IS7).

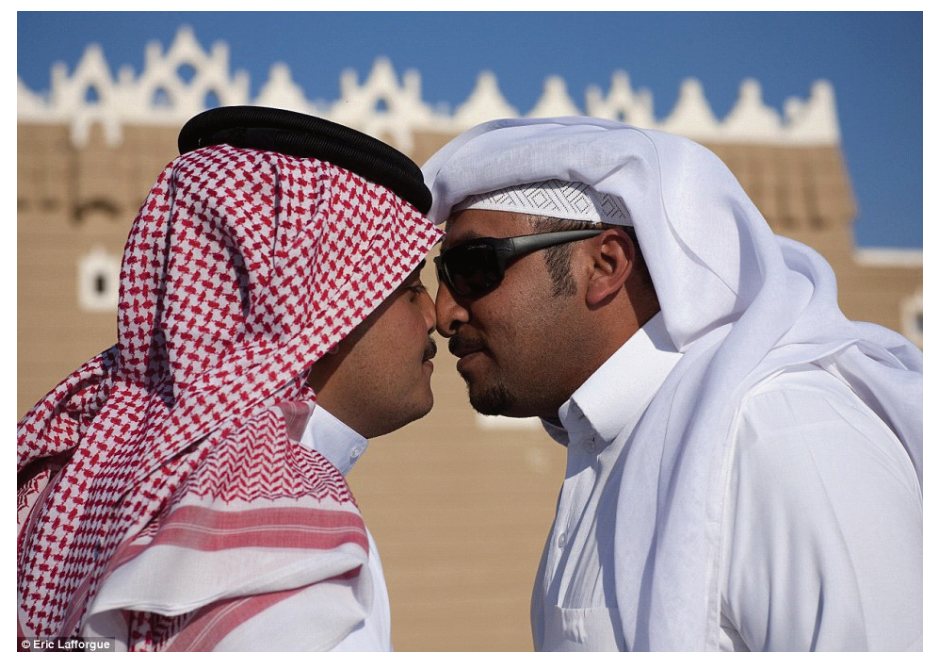

Illustration no. 10. Rubbing noses as a greeting gesture 
Women may also perform this custom as well, but only between themselves. Nevertheless, it is barely seen in public. What is more, as it is considered as a tribal custom, mostly performed by Arabs in Saudi Arabia, it would not be purposeful for not Arabic people to rub their noses.

\subsection{1. 'Kunik' as a greeting gesture}

'Kunik' greeting gesture which involves pressing the nose and upper lip against the skin (mostly of the cheeks or forehead), and breathing in. This gesture performed by Inuit people and is employed by them into a traditional greeting. It is a form of expressing affection, mostly between family members and beloved ones. A common misconception is that Inuit greeting gesture is erotic but it should rather be perceived as intimate greeting gesture which is performed by people who, when they meet outside, often because of the cold weather have little except their noses and eyes exposed.

"The Kunik greeting gesture was described in reports of a group of Alaska Native people touring the United States with entrepreneur Miner W. Bruce in the 1890s: "Mr. Bruce yesterday introduced Kerlungner and Wearner that in this country they should not rub noses, and to close the lesson the two young women kissed each other in the new style for a beginning, both seeming to fear that they looked silly as they did it" (IS8).

As it can be observed there exists many different greeting gestures all around the world. Nevertheless, they differ not only across countries but also across cultures, traditions and religions. Each of presented greeting gesture has its own history and

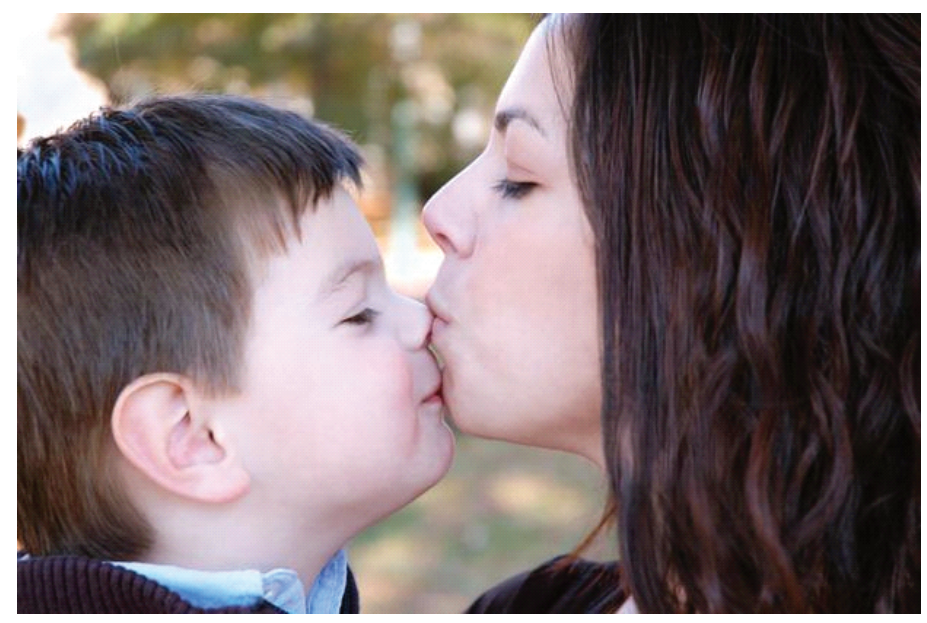

Illustration no. 11. Kunik as a greeting gesture 
is perceived as a distinct custom. What is more, depending on these aspects, greeting gestures may apply different meanings or simply be inappropriate in other cultures. Thus it is better to get familiarize with them in order not to create misunderstandings in interpersonal communication and underline empathy and build peaceful communication rituals among communicators.

\section{Research methodology}

The aim of the present research, which is based on a questionnaire, is to verify the thesis whether different greeting gestures evoke more empathy and which greeting gestures present across cultures may build more empathy and peace in the communication process. The questionnaire was prepared in Polish language and all our respondents were Polish citizens ( 82 respondents: 52 women and 30 men). The questionnaire consists of twenty two close-ended questions about different greeting gestures from around the world. Firstly, respondents were shown photographs of greeting gestures (see illustrations above (1-11)) and then they were asked to mark their answers on a scale (from 1 at the lowest level to 10 at the higher level) to what extent the given gesture evoke the feeling of empathy in them. The interviewee could also add a short comment at the end of each question. The last two multiplechoice questions concerned which of all the presented, to our respondents, greeting gestures evoke the highest feeling of empathy and which the lowest.

\section{The research results}

As mentioned before the aim of the present research, which was based on a questionnaire, was to find out which greeting gestures evoke more empathy and thus build up peace in human communication.

The data in tables is presented below:

Q1. Does the gesture of greeting by shaking hands evoke a feeling of empathy?

82 answers

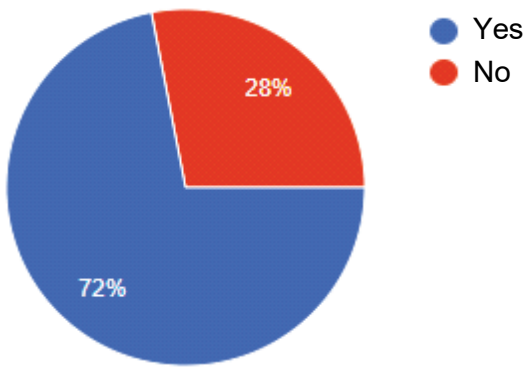

Table 1 
Out of 82 respondents, $72 \%$ answered yes to that question but $28 \%$ answered that such greeting gesture does not evoke empathy for them. On the scale it is visible that handshake is in assessed in the middle because the most common answer for almost $20 \%$ is 5 , but what is more another frequent answers are 6 and 8 . Only $5 \%$ of the respondents marked 10 (the highest level of empathy). Moreover, for $11 \%$ of the respondents the handshake is not an empathic gesture and they marked 2 on the scale. Additionally, the respondents had a chance to add comments. There are positive ones as well as the negatives.

- "Respectful and friendly greeting gesture."

- "Giving and shaking hands are the invitations to contact which in my opinion evoke empathy."

- "It is one of the natural greeting gestures. For arousing empathy the strength of the handshake is also very important."

- "Official handshake so empathy is quite low."

- "The handshake is quite formal and therefore does not evoke empathy."

Q2. Does the gesture of greeting by kissing evoke a feeling of empathy?

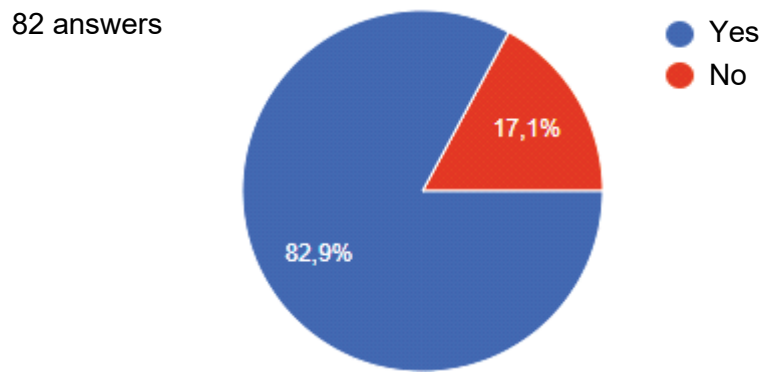

Table 2

A clear majority of the respondents (almost 83\%) agreed that kissing as the greeting gesture evokes empathy. However, $17 \%$ of them answered negatively. It is also well-visible on the scale because nearly $27 \%$ of the respondents assessed this gesture as solid 8 , what is more almost $16 \%$ marked the highest point (10). However, for $11 \%$ of the respondents the kissing gesture is measured as weak 2 and does not evoke empathy. Moreover, respondents the handshake is not an empathic gesture and they marked 2 on the scale. Additionally, the respondents had a chance to add comments. There are positive ones as well as the negatives.

- "Friendly greeting."

- "The expression of sympathy, so it evokes empathy."

- "Respect, warm relations."

- "I find a greeting kiss very nice."

- "A very personal gesture, only with your loved ones."

- "Greeting each other with a kiss is reserved for people who are related." 


\section{Q3. Does the greeting gesture by bowing evoke a feeling of empathy?}

82 answers

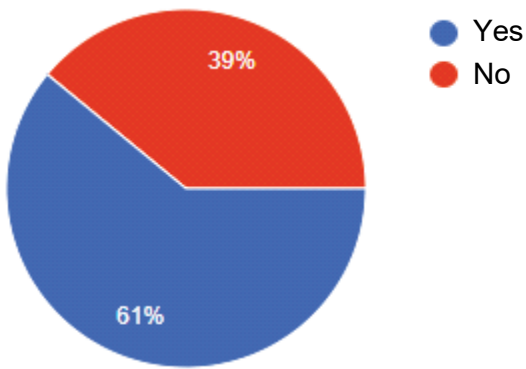

Table 3

Out of 82 respondents, $61 \%$ answered affirmatively to that question but $39 \%$ did not agree that bowing as a greeting gesture can evoke empathy. The grading scale is not so obvious and clear. For those who agreed that this type of greeting gesture evoke empathy the grade on scale is between 5 and 7 . However, for those who did not agree the scale varies between 1 and 3. Additionally, the respondents had a chance to add comments. There are positive ones as well as the negatives.

- "A gesture characteristic for eastern cultures. Personally, I expressed the feeling of empathy as quite low because I do not come from this culture. Nevertheless, in the East, the gesture is perceived as an expression of respect and knowledge of the social etiquette."

- "In our culture it is rarely seen, so it is hard for me to judge whether it evokes empathy because I have never experienced it."

- "An interesting way of showing respect".

- "A gesture that is culturally quite distant."

- "Such a gesture is more appreciated in Eastern culture than in Europe."

- "For me it is more respect than empathy."

- "The highest level of appreciation and honor for another human being. Trust, empathy, respect."

\section{Q4. Does the greeting gesture by bowing and handshake evoke a feeling of empathy?}
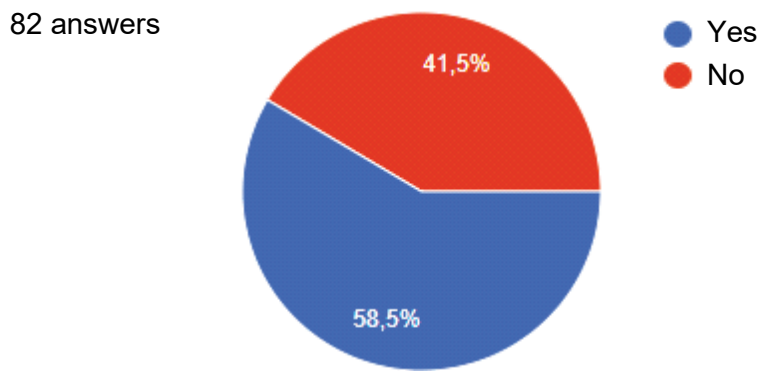

Table 4 
Out of 82 respondents, almost $59 \%$ agreed that bowing and handshake as greeting gesture evokes empathy. About $41 \%$ answered negatively and for them it did not evoke empathy. The grading scale is not so obvious and clear. For those who agreed that this type of greeting gesture evoke empathy the grade on scale is between 5 and 7 . However, for those who do not agree the scale varies between 1 and 2. Additionally, the respondents had a chance to add comments. There are positive ones as well as the negatives.

- "It mainly refers to Asian culture."

- "For me, it expresses most respect and gratitude."

- "As the previous one, but with even more dedication and respect."

- "For me it is more respect than empathy."

- "A matter of culture."

- "Pretty friendly greeting gesture, but also with distance."

\section{Q5. Does the greeting gesture by folding hands together with the fingers pointing upwards (the so-called "Namaste" gesture) evoke a feeling of empathy?}

82 answers

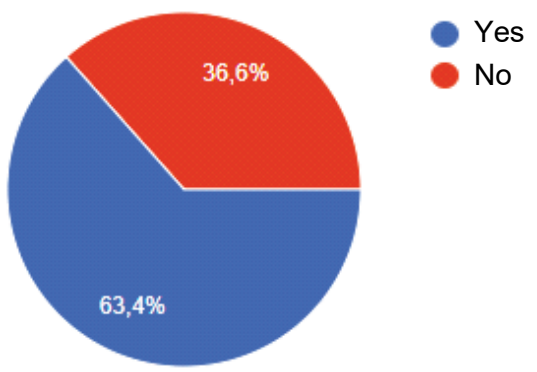

Table 5

Out of 82 respondents, almost $64 \%$ answered that such greeting gesture evokes their empathy, however nearly $36 \%$ did not agree that "Namaste" can evoke empathy. The grading scale is not so clear and obvious. For those whose "Namaste" evoke empathy it is graded as $7(15 \%)$ or $8(12 \%)$. However, when "Namaste" do not evoke any feelings of empathy the scale varies between $1(11 \%)$ to $3(16 \%)$. Additionally, the respondents had a chance to add comments. There are positive ones as well as the negatives.

- "A greeting from another reality, abstract to our standards."

- "Confident gesture."

- "Cultural respect."

- "It did not evoke positive emotions in me, I do not know why."

- "It is similar to the bowing attitude - showing respect and seems to inspire empathy as well."

- "I watch a lot of Bollywood films, they always showed this gesture beautifully and emotionally."

- "As in the previous cases, it is difficult to assess the scale of empathy because I have never experienced such a gesture."

- "It evokes oriental associations, rather cultural issues." 
Q6. Does the greeting gesture by rubbing hands evoke a feeling of empathy?

82 answers

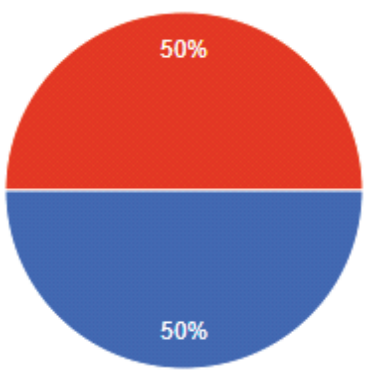

Table 6
Yes

No

$50 \%$ of the respondents agreed that rubbing hands can evoke empathy, and at the same time $50 \%$ responded negatively and decided that such greeting gesture does not evoke empathy at all. On the grading scale the most common grade is 1 (almost $21 \%$ ) so the lowest level of empathy then 2 (almost 16\%). However, when it comes to higher levels of empathy, the most frequent grade is 8 (nearly 14\%). Additionally, the respondents had a chance to add comments. There are positive ones as well as the negatives.

- "It reminds me of compassion. Each person while rubbing their hands can feel the touch. Gentle rubbing is related to delicacy, sensitivity so also empathy."

- "The gesture is unnatural in our culture but it certainly requires some feelings so that it is perceived as unpleasant."

- "It looks very intimate and friendly."

- "It is weird, too much touching."

- "Quite personal greeting gesture."

- "A rare, culturally alien greeting."

- "It seems to be a very intimate and gentle gesture that brings people together."

- "Not in Polish culture."

- "I have never greeted like that, but I have the impression that I would not like such greeting, hence the low rating."

\section{Q7. Does the greeting gesture by placing the head against the hand evoke a feeling of empathy?}

82 answers

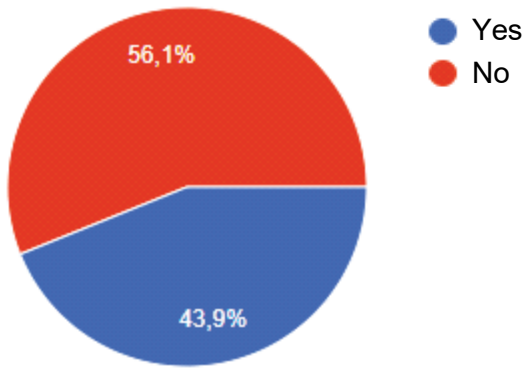

Table 7 
Out of 82 respondents, almost $56 \%$ of the respondents answered negatively to this question and stated that this type of greeting gesture does not evoke empathy. However, almost $44 \%$ agreed that placing the head against the hand evokes empathy. On the grading scale the most frequent answer is 1 (almost 21\%) and 2 (nearly $19 \%$ ). Nevertheless, there are also the higher grades such as 8-10 (about 6\%). Additionally, the respondents had a chance to add comments. There are positive ones as well as the negatives.

- "A greeting from different cultural background seems quite artificial."

- "It is associated with humiliation in a negative sense."

- "I would feel myself uncomfortable in such a situation."

- "This gesture is an expression of respect, but the people in the photo are in a good relationship and you can see positive feelings on both sides."

- "It seems nice but I would only be able to do it with my relatives."

- "A specific gesture."

- "This is the maximum form of paying respect to someone, when at the same time we bow, we respect someone, and touch the other's hand with forehead."

- "It is also close physical contact which in my opinion is empathic."

\section{Q8. Does the greeting gesture by rubbing noses evoke a feeling of empathy?}
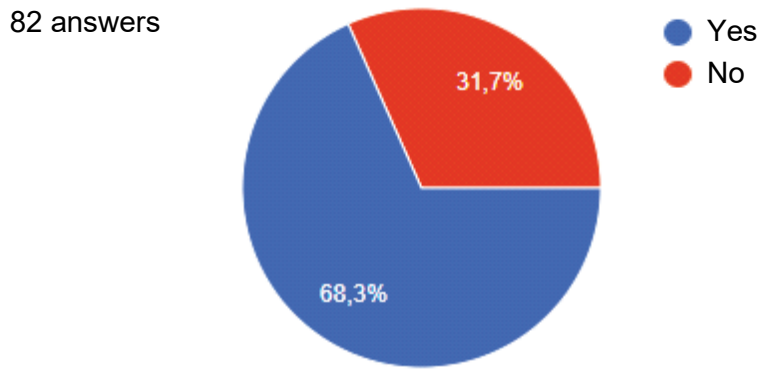

Table 8

Out of 82 respondents, nearly $69 \%$ agreed that rubbing noses as a greeting gesture evoke empathy, however almost $31 \%$ responded negatively to this question. The grading scale is not so clear and obvious. The most frequent answer is 8 (about 15\%) and 10 (about 14\%). For the lower points the most common answer is 1 (almost $13 \%)$ and $2(11 \%)$. Additionally, the respondents had a chance to add comments. There are positive ones as well as the negatives.

- "This is a bit of violation of my comfort zone."

- "A cultural curiosity, completely different from the standard greetings in our culture." 
- "In my opinion, only people in good relationship and without conflict can communicate with this gesture."

- "The gesture itself may evoke empathy but the greeting itself is not quite so."

- "It violates my comfort zone."

- "Personal association with childhood, rubbing noses probably influenced my ability to empathize with this gesture."

- "The photo evoke empathy, it is so sweet."

- "I find it a very cute greeting, although it is a bit alien to me."

- "A matter of culture, quite a personal greeting."

\section{Q9. Does the greeting gesture by showing a tongue evoke a feeling of empathy?}

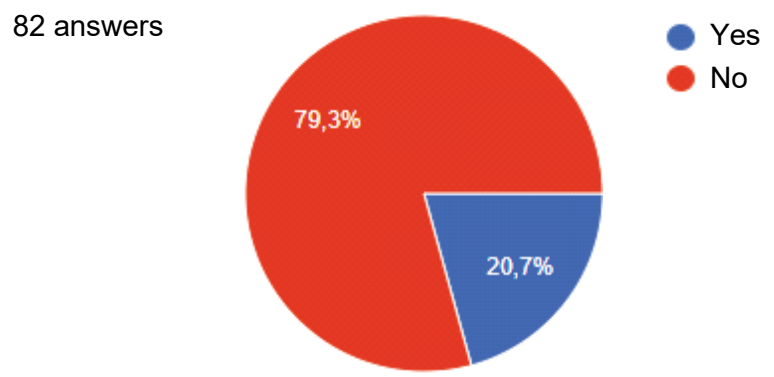

Table 9

Only $20 \%$ of the respondents answered affirmatively to this question that it may actually evoke empathy. However, almost $80 \%$ did not agree that showing tongue in a greeting gesture evoke empathy. The grading scale is clear and obvious. The most frequent grade is 1 (almost 56\%), however there also appears the highest grade 10 but only for $5 \%$ of the respondents. Additionally, the respondents had a chance to add comments. There are positive ones as well as the negative.

- "Very friendly and fun gesture."

- "A form of greeting that in our culture would be called extremely rude."

- "I associate showing tongue with children who do not like something."

- "As funny as the photo is, this form of greeting is not empathetic to me."

- "I think it would be easily accepted among young people."

- "It is perceived as a disrespectful gesture in our culture."

- "It is definitely culturally conditioned. In Poland, such gesture is uncultured and inelegant. Thus, it does not evoke empathy for me."

- "It is fun but hardly empathetic."

- "I do not know this way of greeting, it does not make me empathetic."

- "In our culture, this is not friendly gesture, so it does not evoke empathy." 
Q10. Does the greeting gesture by touching noses evoke a feeling of empathy?

82 answers

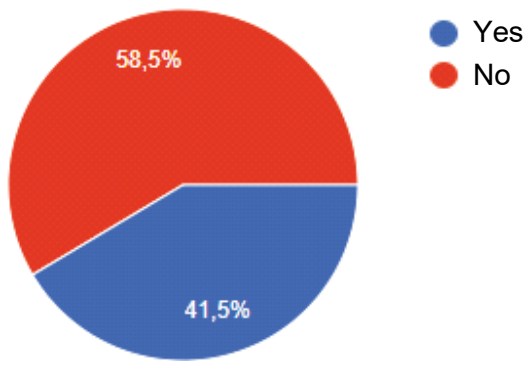

Table 10

Out of 82 respondents, almost $59 \%$ did not agree that touching noses as greeting gesture evoke empathy, however nearly $41 \%$ agreed that it may evoke empathic feelings. On the grading scale the most frequent grade is 1 (about $31 \%$ ) and for the higher grades the most common answers are 7 (almost 10\%) and 10 (nearly 6\%). Additionally, the respondents had a chance to add comments. There are positive ones as well as the negatives.

- "This form of greeting is too different for our culture."

- "This kind of intimate greeting provides me mixed feelings."

- "Too close and too intimate."

- "A matter of culture."

- "Depending on the relationship, this gesture may be perceived differently."

- "Pretty friendly and kind of intimate."

- "It looks like a form of showing affection which evokes my empathy."

- "An unusual, quite personal greeting gesture."

\section{Q11. Does the greeting gesture by kissing and touching nose/chin evoke a feeling of empathy?}

82 answers

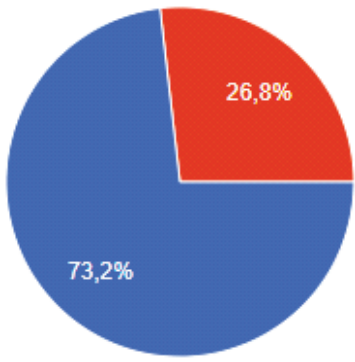

Table 11 
It is visible that nearly $73 \%$ answered affirmatively that such greeting gesture may evoke empathy, however almost $27 \%$ did not agreed and answered negatively. On the grading scale the most frequent answer is 10 (about 21\%) and also 7 (about $13 \%$ ). However, the most common lowest answers are 1 (nearly 10\%) and 2 (almost $9 \%$ ). Additionally, the respondents had a chance to add comments. There are positive ones as well as the negatives.

- "A form of greeting reserved only for very close people."

- "This photo shows a close relationship, and in my opinion the people in it show respect and empathy."

- "Only in the closest circle."

- "It definitely evokes empathy."

- "This gesture indicates a close relationship in which there must be empathy to make such close-ups at all."

- "Caring gesture."

- "Sweet and adorable, it evokes smile and empathy."

- "A very personal greeting gesture, only with loved ones."

\section{Q12. Which of all the greeting gestures evoke the highest level of empathy?}

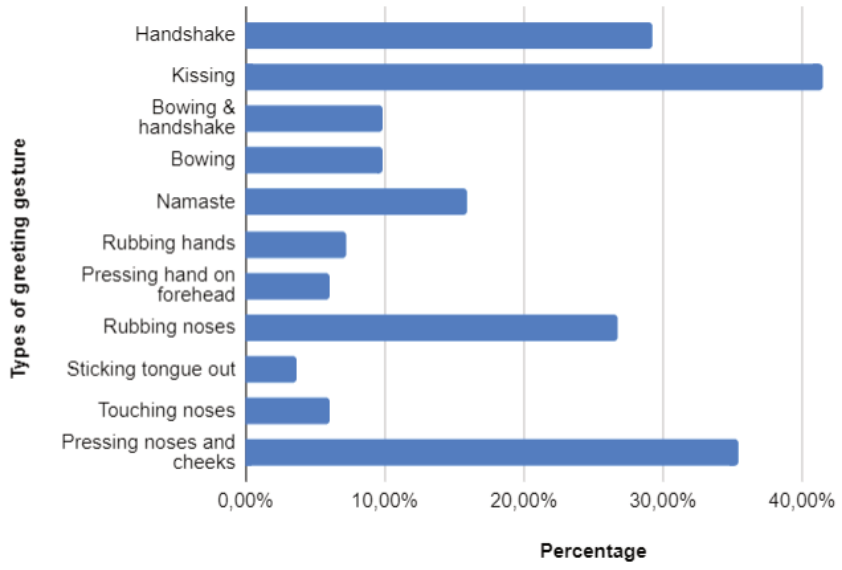

Table 12

The greeting gesture which evoked the highest level of empathy among respondents is kissing gesture (nearly $42 \%$ ). The second gesture that evoked the most empathy is kissing and touching nose/chin (almost 36\%). The third such greeting gesture is shaking hands (about $30 \%$ ) and the fourth is rubbing noses (nearly 27\%). 
Q13. Which of all the greeting gestures evoke the lowest level of empathy?

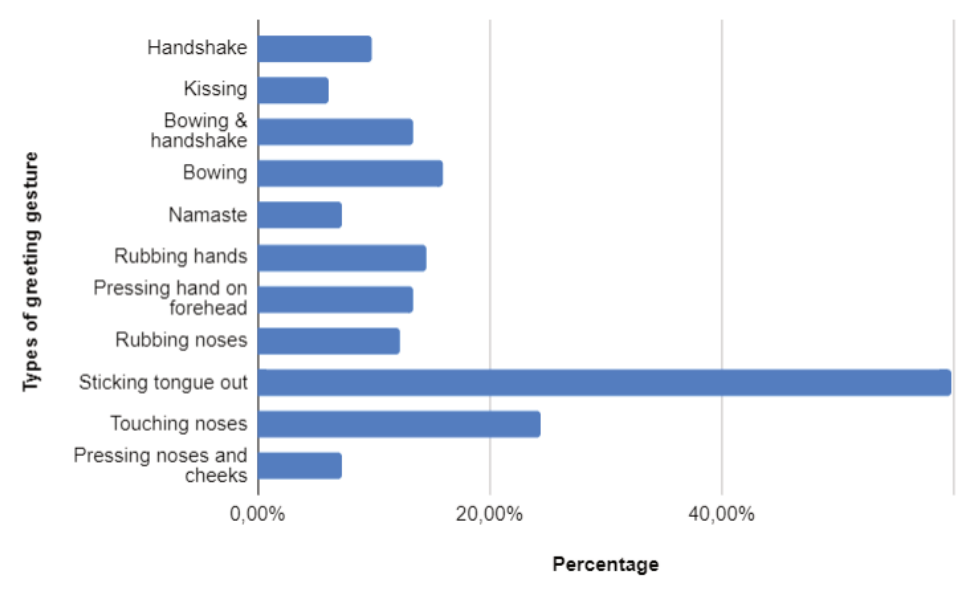

Table 13

The greeting gesture which evoked the lowest level of empathy in respondents is sticking/showing tongue out (nearly 60\%). The second gesture that evoked the lowest feeling of empathy is touching noses (about 25\%). And the third such greeting gesture is bowing (almost 16\%).

\section{Research findings}

The collected data shows that there are four greeting gestures which evoke the highest level of empathy and thus may build peace among communicators. They are respectively as follows: European kissing gesture, 'Kunik' gesture from Greenland, European handshake and Maori rubbing noses. It can be assumed that European greeting gestures such as handshake and kissing evoke the highest level of empathy because they are those which are commonly and widely used by the respondents and it is perhaps easier to have more empathic feelings towards these gestures. Nevertheless, the two remaining examples - 'Kunik' from Greenland and rubbing noses from New Zealand also evoke many positive feelings and thus evoke a lot of empathy. It can be assumed that even though such greeting gestures are distant from those European ones, they are perceived as kind and friendly.

What is more, there are two greeting gestures which evoke the lowest level of empathy, they are as follows: Tibetan sticking tongue out and Arabic touching noses. Those examples present greetings from three different and distant countries and cultures. Nevertheless, the lowest empathy evokes sticking tongue out. This form of greeting gesture is perceived as highly disrespectful. It is also treated as uncultured and strongly inelegant. What is more, this remote greeting gesture not only does not 
evoke empathy but also is rather perceived as highly rude, inelegant and out of respect. It is probably culturally conditioned because in Polish culture sticking tongue out means showing disrespect and is associated with being impolite to others. Moreover, another greeting gesture which evokes the lowest level of empathy is Arabic touching noses. The so called 'Nose kiss' is the form of greeting which is very different and distinct for Polish respondents, so that it is perceived as highly unusual and quite personal. What is more, it is very intimate and close greeting gesture which evokes a lot of mixed feelings. This example confirms that when the greeting gesture requires more physical contact than only handshake or simple kissing, people do not feel empathy and it is out of their comfort zone.

\section{Conclusions}

The conducted research has shown that different greetings gestures across cultures are perceived as an important element of interpersonal communication and most of them do evoke the feeling of empathy and thus may build peaceful communication between communicators. Greeting gestures are extremely important gestures in human culture. Their communicative power and significance lie in building positive potential, for they directly serve to remove tensions between communicators that may occur within one but also across different cultures. The empathic and peace building value of all presented greeting gestures ought to be cherished as a central gestural interaction engine which human beings developed in the course of human evolution.

\section{Bibliography}

AÇEV, 2012. "Building a generation of reconciliation: the role of early childhood development in peace building". Istanbul: AÇEV. [https://www.acev.org/en/kaynaklarimiz/arastirmalarimiz-ve-yayinlarimiz] (retrieved 20.06.21)

Ahmad, N. 2015. "A study of modes of greetings in global perspective with particular reference to Urdu speech community in India". MJAL. 48-122.

Barrich, M.R., Darnold, T.C., Dustin, S.L. and G.L. Stweart. 2008. "Exploring the handshake in employment interviews". Journal of Applied Psychology 93. 1139-1146.

Dresser, N. 1997. "On sticking out your tongue". Los Angeles Times. https://www.latimes.com/ archives/la-xpm-1997-nov-08-me-51420-story.html (retrieved: 20.06.21)

Frijhoff, W. 1991. "The kiss sacred and profane: reflections on a cross-cultural confrontation". In: Bremmer, J.N. and H. Roddenburg. 1991. A cultural history of gesture. Groningen: Polity Press. 210-236

Hall, P.M. and D.A.S. Hall. 1983. "The handshake as interaction". Semiotica 45. 249-264.

Huwer, J. 2003. "Understanding handshaking: the result of contextual, interpersonal and social demands". https://scholarship.tricolib.brynmawr.edu/bitstream/handle/10066/757/2003HuwerJ.pdf? sequence $=5 \&$ isAllowed $=y$ (retrieved: 20.06 .21 ) 
Kumar, N. 2001. "Namaste: the significance of a Yogic greeting". Exotic India Art.

Lundmark T. 2009. Tales of Hi and Bye: greeting and parting rituals around the world. Cambridge: Cambridge University Press

Puppel, J. 2019. "Some observations on the handshake as a crucial indicator of the empathic and peacebuilding culture". Scripta Neophilologica Posnaniensia XIX. 135-142.

Ponton, D. 2014. "The pragmatics of the handshake: a politeness index in British and Italian usage". Via Vittorio Emanuele 8. 60-76.

Remland, M.S., Jones, T.S., Foeman, A. and D.R. Arevalo. 2014. Intercultural communication: a peacebuilding perspective. Long Grove: Waveland Press.

Schirch, L. 2005. Ritual and symbol in peacebuilding. Bloomfield: Kumarian Press.

Schroeder, J., Jane, L.R., Gino, F. and M.I. Norton. 2019. "Handshaking promotes deal-making by signaling cooperative intent". Journal of Personality and Social Interpersonal Relations and Groups Processes 116. 743-768.

Scroope, Ch. 2017. "Filipino culture". https://culturalatlas.sbs.com.au/filipino-culture/filipino-culturereferences\#filipino-culture-references (retrieved: 20.06.21)

Singh, R., Singh, G. and V. Singh. 2020. "Namaste: The traditional Indian way of greeting goes global during coronavirus disease (COVID-19) pandemic". Journal of the Anatomical Society of India. Vol. 69. 65-66.

White, J.M. 2014. “Tibet in the 1930s: Theos Bernard's Legacy at UC Berkeley". Cross-Currents e-Journal 13.

\section{Internet Sources}

IS1: Global Portal for Diplomats "Cultural Etiquette" - http://www.ediplomat.com/np/cultural_ etiquette/ce_cn.htm (retrieved: 20.06.21)

IS2: The Vedanta Kesari. 2012. "Namaste - the Indian Way of Greeting" https://www.esamskriti. com/essays/pdf/15-18-Why-do-we-RKM-18.pdf (retrieved: 20.06.21)

IS3: Hays, J. 2015. "Customs, manners and etiquette in Malaysia". http://factsanddetails.com/southeastasia/Malaysia/sub5_4b/entry-3639.html\#chapter-1 (retrieved: 20.06.21)

IS4: Diep, N. 2019. "Mano or pagmamano - an honoring gesture in Filipino culture" The Voice of Vietnam - VOV WORLD. https:/vovworld.vn/en-US/cultural-rendezvous/mano-or-pagmamano-anhonoring-gesture-in-filipino-culture-800534.vov (retrieved: 20.06.21)

IS5: Rivera, L. 2019. "The Maori Hongi greeting of New Zealand”. TripSavvy. https://www.tripsavvy. com/what-is-a-hongi-1464086 (retrieved: 20.06.21)

IS6: Evason, N. 2019. "Saudi Arabian Culutre". https://culturalatlas.sbs.com.au/saudi-arabian-culture/ saudi-arabian-culture-greetings (retrieved: 20.06.21)

IS7: Saloom, A.A. 2012. "Ask Ali: Why rubbing noses is more than just a custom". The National. https://www.thenationalnews.com/arts-culture/ask-ali-why-rubbing-noses-is-more-than-just-a-custom1.366159 (retrieved: 20.06.21)

IS8: “Eskimo kissing” https://en.wikipedia.org/wiki/Eskimo_kissing\#cite_note-5 (retrieved:20.06.21)

\section{Illustrations Sources}

1. Illustration no. 1 - https://www.askmen.com/money/career/what-your-handshake-says-about-you.html (retrieved: 20.06 .21 )

2. Illustration no. 2 - https://worldwithtj.wordpress.com/2015/09/30/ways-of-greeting-in-different-coun tries/ (retrieved: 20.06.21)

3. Illustration no. 3 - https://www.quickbase.com/blog/dynamics-of-respect-in-the-workplace?hcb=1 (retrieved: 20.06.21) 
4. Illustration no. 4 - https://www.opodo.co.uk/blog/greetings-around-the-world/ (retrieved: 20.06.21)

5. Illustration no. 5 - https://www.learnreligions.com/what-does-namaste-mean-1770004?utm_campaign $=$ shareurlbuttons\&utm_medium $=$ social\&utm_source $=$ pinterest (retrieved: 20.06 .21$)$

6. Illustration no. 6 - https://www.opodo.co.uk/blog/greetings-around-the-world/ (retrieved: 20.06.21)

7. Illustration no. 7 - https://www.opodo.co.uk/blog/greetings-around-the-world/ (retrieved: 20.06.21)

8. Illustration no. 8 - https://www.learnreligions.com/what-does-namaste-mean-1770004?utm_cam paign=shareurlbuttons\&utm_medium=social\&utm_source=pinterest (retrieved: 20.06 .21$)$

9. Illustration no. 9 - https://www.opodo.co.uk/blog/greetings-around-the-world/ (retrieved: 20.06.21)

10. Illustration no. 10 - https://www.dailymail.co.uk/travel/travel_news/article-3428268/Lifting-veilIncredible-pictures-Eric-Lafforgue-life-REALLY-like-Saudi-Arabia-nose-kissing-men-wear-

flowers-heads.html (retrieved: 20.06.21)

11. Illustration no. 11 - https://worldwithtj.wordpress.com/2015/09/30/ways-of-greeting-in-differentcountries/ (retrieved: 20.06.21) 
